\title{
Development Strategy of the Clothing Marketing in China from the Perspective of Network Marketing
}

\section{Chengxi Wang*}

College of Mechanical and Electrical Engineering, Xi'an Polytechnic University, Xi'an 710048, Shaanxi Province, China.E-mail: 1269755213@qq.com

\begin{abstract}
Network marketing is a new thing for adapting to the development of network technology and the social change in the era of information network. The progress of science and technology, the change of consumer concept and the aggravation of business competition promote its emergence and development. As a new marketing method, network marketing will inevitably greatly affect the sales of clothing enterprises. Based on the connotation and characteristics of network marketing, this paper first expounds the main direction of clothing network marketing development, then constructs a multi-network marketing system from the aspects of product quality, brand construction, user tendency, real-time interaction, online and offline, and finally improves the network marketing system. It is expected to provide the corresponding references for the innovation of China's clothing marketing work under the background of Internet.
\end{abstract}

Keywords: Clothing Marketing; Network Marketing; Characteristics; Role; Development Strategy

\section{Introduction}

Network is the trend of development in the world today. The emergence of network marketing which integrates network technology and marketing has brought profound changes to human life style. Nowadays, the "finger economy" spawned by the mouse is growing rapidly with unstoppable force, and the clothing industry is also taking this free ride to the $\mathrm{E}$ era. As a new marketing method and business philosophy, online marketing has been accepted by the clothing field and quickly applied to the clothing marketing practice ${ }^{[1]}$. At present, it is common for clothing enterprises to carry out network marketing, but how to use network marketing more effectively to improve the business performance of clothing enterprises is the theme that the clothing industry concerns about.

\section{Analysis of network marketing characteristics}

Network marketing is a marketing process that establishes communication between enterprises and consumers through the information network platform to realize the transaction of products and services. This marketing is mainly supported by modern information network technology, that is to establish the Internet platform, and realize the clothing design, the purchase, the production, the sale and series of links. and realizes the clothing enterprise management marketing. To realize the marketing of clothing enterprises, the essence is to combine the network with the marketing process and realize the marketing strategy of clothing enterprises. In general, network marketing is characterized by universality, economy and interactivity. See Table 1 for the specific situation.

Copyright (C) 2020 Chengxi Wang

doi: $10.18282 / \mathrm{ff} . \mathrm{v} 9 \mathrm{i} 2.888$

This is an open-access article distributed under the terms of the Creative Commons Attribution Non-Commercial License

(http://creativecommons.org/licenses/by-nc/4.0/), which permits unrestricted non-commercial use, distribution, and reproduction in any medium, provided the original work is properly cited. 


\begin{tabular}{cl}
\hline Main characteristics & \multicolumn{1}{c}{ Specific performance } \\
\hline \multirow{2}{*}{ Universality } & $\begin{array}{l}\text { The range of information transmitted by the network is larger than that of other ways, and the } \\
\text { marketing information can be conveyed through the network in clothing marketing. } \\
\text { Economy }\end{array}$ \\
& $\begin{array}{l}\text { Network marketing simplifies marketing links, saves manpower and material resources and } \\
\text { other costs, and reduces logistics and improves efficiency. } \\
\text { Through the direct contact of email and online trading system, the buyer and seller can obtain } \\
\text { the customer demand accurately, take the customer as the value orientation, and enhance the } \\
\text { clothing marketing effect. }\end{array}$ \\
\hline
\end{tabular}

Table 1. Main characteristics of network marketing

\section{The development trend of clothing marketing from the perspective of network marketing}

According to the survey data, the online shopping transaction volume of clothing in China reached more than 500 billion yuan in 2019, becoming one of the important ways of domestic clothing consumption. As a more active product in the network marketing products, there has been a relatively perfect marketing system for clothing, showing the following development trends.

(1) The interaction between clothing enterprises and customers is enhanced. Clothing network marketing is no longer a single organization and implementation of enterprises, but an activity involving consumers, so the clothing network marketing has more personalized characteristics. For example, celebrities and fans are invited to participate in the new clothing release conference, which is broadcast on the Internet to interact with the vast number of potential customers, so as to achieve extensive publicity effect.

(2) Search engine marketing will remain the dominant mode of network marketing for a considerable period of time. Fan base is the most basic element of clothing network marketing. Each clothing brand needs to get enough fans first in order to obtain benefits from network marketing. For example, embedding a brand in the clothes worn by the actors in a popular online TV series can attract a lot of fans.

(3) The creativity of clothing network marketing becomes the competition core strength. Internet users choose Internet media in a variety of ways, and the choice of behavior is difficult to predict. In order to better convey information to users, clothing enterprises should diversify their marketing, and create new and unique clothing network marketing ideas. The current Internet celebrity economy is a good example, popular microblogs with hundreds of thousands or even millions of followers can create huge profits in a short time by means of novel, dynamic and intimate marketing methods, and the result is immediate ${ }^{[2]}$.

(4) Customized clothing will be increasingly popular in the market. Due to the personalized pursuit of values, the mass strategy of big brand clothing can no longer meet the needs of the market, and users need more personalized products.

\section{Development strategy of clothing marketing from the perspective of network marketing}

\subsection{Ensuring product quality and realizing personalized development}

A good brand is characterized by high quality assurance, which is the essential condition to determine the product market and sales effect. Quality is the life of the brand and the guarantee of obtaining the reputation of consumers. With the development of the market and the intensification of competition, consumers are becoming more and more picky. In the process of clothing network marketing, it is necessary to ensure the quality of the products to make the brand popular.

With the development of the times, consumer demand increasingly presents the characteristics of "personalization", 
and the pursuit of being different has become the mainstream of consumer psychological development. Therefore, clothing marketing should focus on the research of consumer needs. Through establishing online user database and according to the specific requirements of different consumers, products can be produced to meet the characteristics of consumer personality. For example, Levis, a famous clothing company in the United States, makes use of the Internet to customize jeans and personally deliver them to consumers.

\subsection{Forming network brand and promoting brand marketing}

With the intensification of market competition, the competition between enterprises has been extended from physical products to services, and network marketing should pay attention to both product quality and service quality.

The network provides a good interactive platform for clothing enterprises and consumers, and enterprises can send relevant information of products to target consumers through the design of websites. In the process of clothing marketing, it is necessary to pay attention to the propaganda and display of clothing, which should be true and detailed $^{[3]}$. The design should be tailored to the needs of consumers, so as to make the website more appealing and fully stimulate the curiosity, conformity and other psychological characteristics of visitors, forcing them to browse the store.

In addition, the website can also provide consumers with fashion information, collocation advice and other related knowledge of clothing. The clothing enterprise should choose reasonable packaging methods and distribution methods to ensure that the goods can be in good condition and timely reach consumers. If consumers want to return clothes purchased online due to the personalized characteristics of clothing itself, the website should reasonably deal with the problem of returned goods, so that consumers can feel that even if the clothes purchased online are not appropriate, they can easily return the goods, so as to reduce the concerns of consumers online clothing purchase.

\subsection{Achieving multiple marketing and improving consumer satisfaction}

In the process of clothing network marketing, the key points of corresponding marketing can be formed by combining the market environment and user tendency. First, using Internet celebrity to introduce fan base. There must be a reason for the popularity of a dress. It may be that the leading actor of a TV series wears the same garment, or a hot figure mentions his or her clothing preference in an interview. A burst point can ignite the passion of consumers and cause the butterfly effect in the Internet world. Second, using big data. In the data age of the Internet, every consumer has data behind every purchase. Through the data law of consumers, the trend of popularity can be analyzed, and the characteristics of individuation can be judged, so as to formulate the corresponding marketing strategy, grasp the pain point of consumption, and realize precision guidance. Third, realizing advanced customization. Clothing enterprises can display all aspects of clothing production on their own platform, from the selection of cloth, production technology, to the design of patterns and other links, so that consumers can see and give their ideas, and have a sense of participation. In the past, advanced customization was the privilege of a few people, and the Internet made it possible to popularize personality customization, so that manufacturers could face the demand directly, thus enhancing the satisfaction of users to the marketing of clothing network.

\subsection{Strengthening the interaction between the two sides to achieve real-time feedback}

In the process of clothing network marketing, enterprises should make their own information feedback system fast and accurate, and only in this way can it ensure the smooth flow of channels and improve consumer satisfaction. For example, enhancing the search function of the website can improve the number of views of the website. When designing online ordering system, it is necessary to improve the operability of ordering and the accuracy of information transmission. According to the website visits, website rankings, user retention rate, user source analysis, keyword analysis, the enterprise can grasp the user needs. It is necessary to form a complete data collection and benign sales interaction through network platform, and achieve effective marketing based on big data and user preferences, so as to fundamentally improve the clothing network marketing benefits. 


\subsection{Combining online and offline and achieving comprehensive after-sale service}

Both network marketing and traditional marketing depend on customer's sense of trust. It is necessary to use a variety of traditional clothing sales and distribution channels to achieve online and offline sales organic combination. It is an advantage to have physical stores, where customers can learn about products and workmanship and have a good foundation of trust after experience. This trust can be transformed into an opportunity to continue shopping online in the future. NUA, an American firm, is using traditional channels to attract customers online ${ }^{[4]}$. After ordering clothes from the Internet, customers can choose their favorite way to conveniently obtain, return and change the selected clothes from the Internet or from the nearest store, so that customers do not have to worry about after-sales service and further cultivate their trust in the brand. Known for its catalog and mail-order catalog, consumers can go directly to the physical store of MecoxLane store, Euromoda, to try on clothes and shoes they see on the website and pick out the best size.

\section{Conclusion}

Network marketing with great marketing advantages is the inevitable trend of the development of clothing marketing channels, and it is a marketing channel mode that meets the needs of the development of new productive forces. Under this background, clothing enterprises need to change from the real booth marketing to a more convenient network platform, open a new mode of thinking, and plan a strategy that accords with the characteristics of network marketing activities. Only by keeping up with such changes and constantly exploring and expanding network marketing channels, can clothing marketing keep up with the development needs of the times and the business efficiency of enterprises be maximized.

\section{References}

1. Zhao L, Zhou J. Analysis on the advantages and disadvantages of clothing network marketing (in Chinese). International Journal of Business and Social Science 2015; 6(4).

2. Liu Y, Li S. Research on marketing strategy of network womenswear brand based on big data statistics. In 2019 34rd Youth Academic Annual Conference of Chinese Association of Automation (YAC). IEEE; 2019 June. p. 90-94.

3. Liu Y, Zhang T. Research on digital marketing strategies of fast fashion clothing brands based on big data. In 2019 34rd Youth Academic Annual Conference of Chinese Association of Automation (YAC). IEEE; 2019 June. p. 552-556.

4. Chen X, Fang G. Analysis on green marketing strategy of clothing firm: Take H\&M for example. In Proceedings of the 2019 International Conference on Management Science and Industrial Engineering; 2019 May. p. 146-150. 